University of New Hampshire

University of New Hampshire Scholars' Repository

Physics Scholarship

Physics

8-1-2004

\title{
High-resolution kinetic energy release distributions and dissociation energies for fullerene ions $C(n)(+), 42<=n<=90$
}

K. Gluch

S. Matt-Leubner

Olof E. Echt

University of New Hampshire, Olof.Echt@unh.edu

B. Concina

P. Scheier

See next page for additional authors

Follow this and additional works at: https://scholars.unh.edu/physics_facpub

Part of the Physics Commons

\section{Recommended Citation}

The following article appeared in J. Chem. Phys. 121, 2137 (2004); doi: 10.1063/1.1768172 and may be found at http://dx.doi.org/10.1063/1.1768172.

This Article is brought to you for free and open access by the Physics at University of New Hampshire Scholars' Repository. It has been accepted for inclusion in Physics Scholarship by an authorized administrator of University of New Hampshire Scholars' Repository. For more information, please contact Scholarly.Communication@unh.edu. 


\section{Authors}

K. Gluch, S. Matt-Leubner, Olof E. Echt, B. Concina, P. Scheier, and T. D. Mark 


\section{AIP $\begin{gathered}\text { molowanat } \\ \text { chemical Physics }\end{gathered}$}

High-resolution kinetic energy release distributions and dissociation energies for fullerene ions $\mathrm{Cn}+, 42 \mathrm{n} 90$

K. Głuch, S. Matt-Leubner, O. Echt, B. Concina, P. Scheier et al.

Citation: J. Chem. Phys. 121, 2137 (2004); doi: 10.1063/1.1768172

View online: http://dx.doi.org/10.1063/1.1768172

View Table of Contents: http://jcp.aip.org/resource/1/JCPSA6/v121/i5

Published by the American Institute of Physics.

Additional information on J. Chem. Phys.

Journal Homepage: http://jcp.aip.org/

Journal Information: http://jcp.aip.org/about/about_the_journal

Top downloads: http://jcp.aip.org/features/most_downloaded

Information for Authors: http://jcp.aip.org/authors

\section{ADVERTISEMENT}
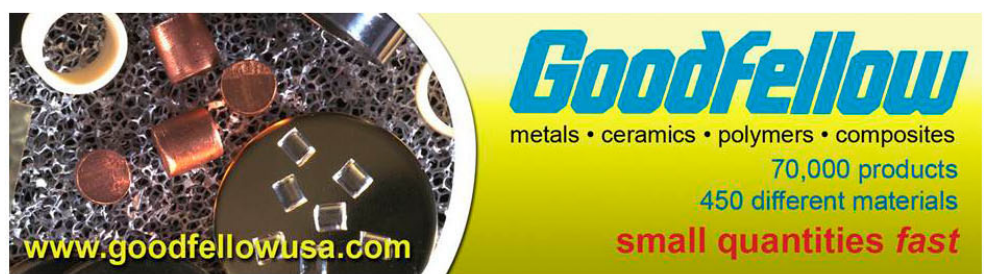


\title{
High-resolution kinetic energy release distributions and dissociation energies for fullerene ions $\mathrm{C}_{n}{ }^{+}, 42 \leqslant n \leqslant 90$
}

\author{
K. Głuch, ${ }^{\text {a) }}$ S. Matt-Leubner, O. Echt, ${ }^{\text {b) }}$ B. Concina, ${ }^{\text {c) }}$ P. Scheier, and T. D. Märk ${ }^{\text {d) }}$ \\ Institut für Ionenphysik, Leopold Franzens Universität, A-6020 Innsbruck, Austria
}

(Received 20 February 2004; accepted 12 May 2004)

\begin{abstract}
We have measured the kinetic energy released in the unimolecular dissociation of fullerene ions, $\mathrm{C}_{n}{ }^{+} \rightarrow \mathrm{C}_{n-2}{ }^{+}+\mathrm{C}_{2}$, for sizes $42 \leqslant n \leqslant 90$. A three-sector-field mass spectrometer equipped with two electric sectors has been used in order to ensure that contributions from isotopomers of different masses do not distort the experimental kinetic energy release distributions. We apply the concept of microcanonical temperature to derive from these data the dissociation energies of fullerene cations. They are converted to dissociation energies of neutral fullerenes with help of published adiabatic ionization energies. The results are compared with literature values. (C) 2004 American Institute of Physics. [DOI: 10.1063/1.1768172]
\end{abstract}

\section{INTRODUCTION}

The stability of fullerenes has been a controversial topic for some time. Several groups have determined the standard enthalpies of formation of $\mathrm{C}_{60}$ and $\mathrm{C}_{70}$ from graphite by calorimetry with high accuracy. The weighted average of the nine experimental values compiled for solid $\mathrm{C}_{60}$ in Ref. 1 amounts to $2322.8 \mathrm{~kJ} / \mathrm{mol}$, or $0.401 \mathrm{eV}$ per atom, with a standard deviation of $2.1 \%$.

Unfortunately, similarly accurate values for fullerenes other than $\mathrm{C}_{60}$ and $\mathrm{C}_{70}$ are not available because those molecules are either not stable in condensed form, or not available in purified form in sufficient quantity. Therefore, the (adiabatic) dissociation energies for the preferred dissociation reactions of isolated (gas-phase) fullerenes,

$$
\mathrm{C}_{n} \stackrel{k_{n}}{\longrightarrow} \mathrm{C}_{n-2}+\mathrm{C}_{2},
$$

cannot be derived from measured thermodynamic quantities, not even for $n=60$ or 70 .

At the same time, the interest in fullerenes has broadened to include larger as well as smaller species. Fullerenes of size $76 \leqslant n \leqslant 94$ have been synthesized and extracted in mass-selected, sometimes even in isomer-selected, form (see Ref. 2 and references therein). Nonclassical fullerenes, such as $\mathrm{C}_{62}$ that includes a four-membered ring, have been purified. ${ }^{3}$ Smaller fullerenes such as $\mathrm{C}_{36}$ (Ref. 4) and $\mathrm{C}_{20}$ (Ref. 5) have been synthesized and characterized. Based on photoelectron spectra it has been concluded that $\mathrm{C}_{82}$ is the most stable fullerene below $\mathrm{C}_{60} \cdot{ }^{6}$ All these fullerenes hold promise for the formation of novel fullerene materials.

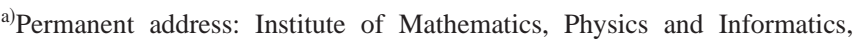
Maria Curie-Sklodowska University, Lublin 20-031, Poland.

${ }^{b}$ Permanent address: Department of Physics, University of New Hampshire, Durham, New Hampshire 03824.

${ }^{c)}$ Present address: Department of Physics and Astronomy, University of Aarhus, DK-8000 Aarhus C, Denmark.

d) Author to whom correspondence should be addressed. Also at Department of Plasma Physics, Comenius University, SK-84248 Bratislava, Slovak Republic; Fax: +43-512-507-2932. Electronic mail: tilmann.maerk @ uibk.ac.at
}

These experimental achievements have prompted a large number of theoretical investigations into the stability of fullerenes, ranging from sizes where fullerenes compete in stability with planar sheets, bowls, or monocyclic rings, ${ }^{7,8}$ to buckyball-sized fullerenes, ${ }^{9-11}$ beyond $\mathrm{C}_{70},{ }^{8,12}$ and to very large fullerenes at the crossover to nanotubes. ${ }^{13,14}$

It is desirable to compare this wealth of theoretical data with experimental values but, as explained above, they are not available for neutral fullerenes. An alternative approach is to measure rate coefficients for the gas-phase reaction,

$$
\mathrm{C}_{n}{ }^{+} \stackrel{k_{n}^{+}}{\longrightarrow} \mathrm{C}_{n-2}{ }^{+}+\mathrm{C}_{2} \text {. }
$$

If one obtains from these experiments the adiabatic dissociation energies, $D_{n}{ }^{+}$of fullerene cations then one may compute the adiabatic dissociation energies for the neutrals from a thermodynamic cycle,

$$
D_{n}=D_{n}^{+}+I E_{n}-I E_{n-2},
$$

where $I E_{n}$ denotes the adiabatic ionization energy of $\mathrm{C}_{n}$.

In this work we will present experimentally determined values for $D_{n}{ }^{+}$, for $42 \leqslant n \leqslant 90$. With the exception of the work by Barran et al., ${ }^{15}$ this size range considerably exceeds the range of all previous experimental studies. Dissociation energies for neutrals will be derived by using recently published experimental and theoretical values for the ionization energies. $^{16}$

Deriving $D_{n}{ }^{+}$from the rate coefficient of reaction (2) faces a number of challenges (see Ref. 17 for an approach that meets these challenges, but the technique is not applicable to fullerenes). One needs to know other quantities, and the relation between them. Frequently an Arrhenius relation is assumed,

$$
k_{n}{ }^{+}=A_{n} \exp \left(-\frac{D_{n}{ }^{+}}{k_{B} T_{e}}\right),
$$

where $T_{e}$ is the emission temperature to be defined later, and $D_{n}{ }^{+}$is the activation energy of the reaction. Kinetic energy 
release distributions (KERD) measured for reaction (2) suggest that it does not feature a reverse barrier. ${ }^{18}$ Therefore, $D_{n}{ }^{+}$is identical to the adiabatic dissociation energy. Recent experimental ${ }^{19}$ and theoretical studies ${ }^{20}$ indicate that $\mathrm{C}_{2}$ attachment to neutral or charged $\mathrm{C}_{60}$ and other fullerenes features a complex reaction path but, again, there is no evidence for a net reaction barrier.

A large uncertainty arises from the preexponential $A_{n}$ and its size dependence. Klots ${ }^{21}$ has argued that a value of $1.6 \times 10^{15} \mathrm{~s}^{-1}$ is appropriate for atomic clusters over a wide range of sizes. In the last few years it has been realized that $A_{60}$ is several orders of magnitude higher than previously thought ${ }^{22-26}$ (also see the recent reanalysis of $A$ factors by Hansen and Campbell ${ }^{27}$ for other elemental clusters).

The other critical quantity in Eq. (4) is the vibrational excitation energy of the metastable complex from which the emission temperature $T_{e}$ is computed. ${ }^{28}$ Very few experiments on fullerenes have been performed where this energy has been controlled directly, such as in sticking collisions at hyperthermal energies $;{ }^{29,30}$ those results, though, pertain to collision complexes (endohedral fullerenes). For bare fullerenes, one has to proceed differently. One may determine the excitation energy from estimated energy deposition functions, ${ }^{31,32}$ from an analysis of the temporal evolution of the dissociation rate and its modification due to competing channels such as radiation, ${ }^{24-26}$ or from the kinetic energy release (KER) for reaction (2). ${ }^{33}$

We have applied this latter method. One of its advantages is its ability to directly provide a measure of the excitation energy that drives the reaction. By contrast, an analysis of metastable fractions ${ }^{15}$ does not provide this information and only yields relative dissociation energies. Several KER measurements have been reported before but, with one exception, ${ }^{34}$ they were restricted to singly or multiply charged fullerenes in the immediate vicinity of $n=60$ or $n=70 .{ }^{18,35-37}$ The data presented here have a greatly improved accuracy because they are recorded with a double focusing mass spectrometer of reversed geometry equipped with a second electric sector. ${ }^{38-40}$ This instrument avoids a number of artifacts that commonly occur in measurements of large clusters that are not isotopically pure. ${ }^{41}$ However, sizeaveraged dissociation energies derived in the present work tend to be approximately $13 \%$ higher than values derived from other experiments in the gas phase, ${ }^{25}$ from calorimetric measurements, ${ }^{1}$ and from theory. ${ }^{10}$

\section{EXPERIMENT}

The apparatus consists of a high-resolution double focusing mass spectrometer (Varian MAT CH5-DF) of reversed Nier-Johnson type BE1 geometry combined with a second electrostatic analyzer $E 2 .^{42}$ Fullerene powder from MER Corporation (either pure $\mathrm{C}_{60}(99.5 \%)$, or $\mathrm{C}_{70}(99 \%)$, or a mixture of higher-order fullerenes specified to contain mainly $\mathrm{C}_{76}, \mathrm{C}_{78}, \mathrm{C}_{84}$, and $\mathrm{C}_{92}$ ) was, without further treatment, evaporated into a vacuum of about $10^{-7}$ Torr by a temperature controlled oven operating at $650-900^{\circ} \mathrm{C}$. The effusive beam of neutral fullerenes is crossed at right angles with an electron beam of $120 \mathrm{eV}$ and a current of about 1 $\mathrm{mA}$. The resulting ions are extracted perpendicular to the fullerene and electron beams and accelerated into the mass spectrometer with $3 \mathrm{kV}$. Ions pass through the first field free region, are momentum analyzed by a magnetic sector field $B$, enter a second field-free region, pass through a $90^{\circ}$ electric sector field $(E 1)$, enter a third field free region $(f f 3$, length $92 \mathrm{~cm}$ ), pass through another electrostatic sector field $(E 2)$, and are detected by an electron multiplier. Referenced to the time of their formation, $\mathrm{C}_{60}{ }^{+}$parent ions traverse $f f 3$ during the time interval $75 \leqslant t \leqslant 91 \mu \mathrm{s}$, equivalent to a most probable time of $82.7 \mu \mathrm{s}$. The corresponding times for other sizes $n$ are obtained by multiplying with $\sqrt{n / 60}$.

Mass-analyzed ion kinetic energy (MIKE) spectra of ions that undergo spontaneous dissociation in $f f 3$ are analyzed by tuning the magnet and first electric sector field to transmit the parent ion (mass $m_{p}$ ), and scanning the sector field voltage of $E 2$. In this mode, $B$ and $E 1$ constitute a double focusing high-resolution mass spectrometer, and $E 2$ will transmit fragment ions (mass $m_{f}$ ) formed in $f f 3$ if the sector field voltage $U_{f}$ is set to

$$
U_{f}=\frac{m_{f}}{m_{p}} U_{p}
$$

These MIKE spectra, together with a scan of the parent ion around voltage $U_{p}$, provide the experimental raw data from which the KERD will be derived.

Of particular concern in the present study was the effect that isotopomers may have on the shape of the MIKE peaks and, therefore, on the values that are derived for the average kinetic energies and dissociation energies. ${ }^{39}$ For example, $\mathrm{C}_{60}$ synthesized from naturally occurring carbon will contain isotopomers of mass $721 \mathrm{u}$ or higher with $49 \%$ probability. When a double focusing mass spectrometer is used to record MIKE peaks, the parent ion beam will not be fully mass resolved because ions from the ion source emerge with a dispersion of kinetic energies. The daughter ions from these different parent ions will be located at slightly different sector field voltages [see Eq. (5)], but they cannot be resolved.

Furthermore, if the parent ion is not isotopically pure, then the mass of a fragment ion is not uniquely determined. For example, the fragment peak arising from $\mathrm{C}_{2}$ loss from $\mathrm{C}_{60}{ }^{+}$parent ions of mass $721 \mathrm{u}$ (containing exactly one ${ }^{13} \mathrm{C}$ isotope) will have contributions from loss of a pure dimer $\left({ }^{12} \mathrm{C}\right)_{2}$, and loss of the mixed dimer ${ }^{12} \mathrm{C}-{ }^{13} \mathrm{C}$. The corresponding fragment ion peaks will be located at different sector field voltages [Eq. (5)], but their separation is usually much smaller than their width which arises from the KER. As a result, an uncritical analysis of the total MIKE peak will lead to KER values that are too large.

These effects have been illustrated in Ref. 39. In the present work the average KER values are either derived from experiments on isotopically pure $\left({ }^{12} \mathrm{C}\right)_{n}{ }^{+}$, or they have been corrected for contamination by other isotopomers based on detailed test experiments combined with theoretical modeling. ${ }^{38}$ Without these precautions, the average KER may be overestimated by as much as $15 \%$. 


\section{DATA ANALYSIS}

Experimental MIKE peaks are usually converted to kinetic energy release distributions $f(\epsilon)$ by removing statistical noise, deconvoluting with the smoothed parent ion peak, differentiating the resulting spectrum, and converting the sector-field voltage to kinetic energies. ${ }^{33,43,44}$ In the present work we have inverted the procedure in order to avoid errors that may arise from the unavoidable data smoothing and deconvolution; details have been described elsewhere. ${ }^{40}$ Strictly speaking, $f(\epsilon)$ is that distribution which, with proper parametrization, provides a best fit (lowest chi square, $\chi^{2}$ ) between a synthetic MIKE spectrum computed from $f(\epsilon)$ and convoluted with the parent ion peak, and the observed MIKE spectrum.

$f(\epsilon)$ reveals the microcanonical temperature $T_{f}$ of the fragment ion ${ }^{45,46}$

$$
f(\epsilon) \propto \epsilon \sigma(\epsilon) e^{-\epsilon / k_{B} T_{f}},
$$

where $\sigma(\epsilon)$ is the capture cross section for the reverse of reaction (2). Comprehensive studies have shown that, for unimolecular dissociation of $\mathrm{C}_{56}{ }^{+}, \mathrm{C}_{58}{ }^{+}$, and $\mathrm{C}_{60}{ }^{+}$(Ref. 40) and some other atomic cluster ions, ${ }^{47}$ the energy dependence of the capture cross section is, within experimental error, indistinguishable from the Langevin cross section, $\sigma(\epsilon) \propto 1 / \sqrt{\epsilon}$. Consequently, $T_{f}$ is related to the average KER by

$$
1.5 k_{B} T_{f}=\bar{\epsilon}
$$

We apply the concept of microcanonical temperatures ${ }^{28,46}$ to compute from $T_{f}$ the dissociation energy $D_{n}{ }^{+}$. To first order, the emission temperature $T_{e}$ in Eq. (4) is the mean of $T_{f}$ and $T_{p}$, the microcanonical temperature of the parent ensemble. The fragment and parent ensembles differ by an energy $D_{n}{ }^{+}$, hence

$$
T_{e}=T_{f}+D_{n}{ }^{+} / 2 C_{m}=T_{p}-D_{n}{ }^{+} / 2 C_{m},
$$

where $C_{m}$ is the microcanonical heat capacity for which we assume the high-temperature limit, $C_{m}=(3 n-7) k_{B}$.

The preexponential $A_{n}$ in Eq. (4) is, for lack of additional information, assumed to be independent of size $n$; we use $A_{n}=2 \times 10^{19} \mathrm{~s}^{-1}$. This is identical to, or very close to, the value used in most other recent studies of unimolecular dissociation of fullerene ions. ${ }^{25,30,34,36,37,48,49}$

Equation (4) also involves the rate coefficient $k_{n}{ }^{+}$. If an evaporative ensemble of cluster ions $\mathrm{C}_{n}{ }^{+}$is sampled at time $t_{n}$ after excitation and if competing cooling channels can be neglected, then the most probable dissociation rate coefficient will be $\mathrm{e}^{21,50}$

$$
k_{n}{ }^{+} \cong 1 / t_{n} .
$$

However, from time-selective measurements of $\mathrm{C}_{2}$ emission rates or metastable fractions, ${ }^{22,25,28,51}$ kinetic energy releases, ${ }^{18,37}$ and electron emission rates ${ }^{52}$ it has been established that thermal radiation can significantly reduce the rate coefficient if $t_{n} \gg 1 \mu \mathrm{s}$. In our analysis we take this into account by replacing Eq. (9) with

$$
k_{n}{ }^{+} \cong R\left(t_{n}\right) / t_{n} .
$$

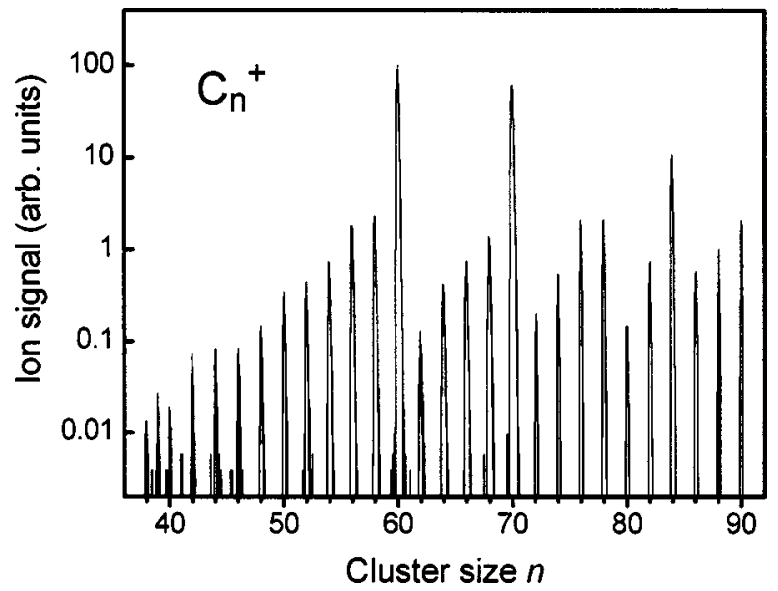

FIG. 1. Composite mass spectrum of fullerene ions $\mathrm{C}_{n}{ }^{+}$formed by electron impact ionization from a mixture of $\mathrm{C}_{60}$ and $\mathrm{C}_{70}(n \leqslant 70)$, and a mixture of higher-order fullerenes.

We estimate the reduction factor $R\left(t_{n}\right)$ from the dissociation rate of photoexcited fullerene cations measured by Tomita et $\mathrm{al}^{25}$ in an ion storage ring. Radiative cooling causes the dissociation rate to drop below the $t^{-1}$ power law. From the data for $\mathrm{C}_{58}{ }^{+}$(Ref. 53) evaluated at $t=81.3 \mu \mathrm{s}$, the time characteristic of our instrument, one finds $R\left(t_{58}\right)=0.29$.

For other sizes we compute the reduction factor as follows: The ion transit time $t_{n}$ through our instrument scales as the square root of $n$ while $R(t)$ scales as $t /\left[\exp \left(t / \tau_{c}\right)-1\right]$ where $\tau_{c} \approx 44 \mu \mathrm{s},{ }^{53}$ hence $R\left(t_{n}\right)$ decreases from 0.35 for $\mathrm{C}_{42}{ }^{+}$to 0.21 for $\mathrm{C}_{90}$. However, we ignore the dependence of the characteristic cooling time $\tau_{c}$ on the dissociation energy, $\tau_{c} \propto\left(D_{n}{ }^{+}\right)^{-5}$ (Ref. 54), which may cause local variations in the radiative cooling correction. ${ }^{25}$ Note that another factor, namely, the linear increase of the radiation intensity with size $n,{ }^{54}$ cancels against the approximately equal size dependence of the heat capacity. Overall, our radiative corrections are estimated to be accurate within a factor of 2 .

\section{RESULTS AND DISCUSSION}

\section{A. Kinetic energy release}

In Fig. 1 we show a composite mass spectrum of fullerene cations obtained by electron impact ionization. Ions of size $n \leqslant 70$ were recorded by vaporizing a mixture of $\mathrm{C}_{60}$ and $\mathrm{C}_{70}$ at a temperature of $450{ }^{\circ} \mathrm{C}$; larger fullerene ions were obtained by vaporizing the mix of higher-order fullerenes at $700{ }^{\circ} \mathrm{C}$. In order to ensure that the cluster ions conform to the evaporative ensemble, we have analyzed ions $\mathrm{C}_{n}{ }^{+}, n \leqslant 58$ produced from $\mathrm{C}_{60}$ powder, ions $\mathrm{C}_{n}{ }^{+}, 60 \leqslant n \leqslant 68$ produced from $\mathrm{C}_{70}$ powder, and larger ions produced from a mixture of higher fullerenes. For comparison, we have also analyzed $\mathrm{C}_{60}{ }^{+}$produced from $\mathrm{C}_{60}$ and found no significant difference in the KER. The reason for this is that measurements of the $\mathrm{KER}$, in contrast to measurements of other quantities such as the dissociation rate coefficients and metastable fraction, are self-selecting. If an ensemble of cluster ions has never undergone dissociation then it may contain a large, unknown fraction of relatively cold species, but those will not decay 


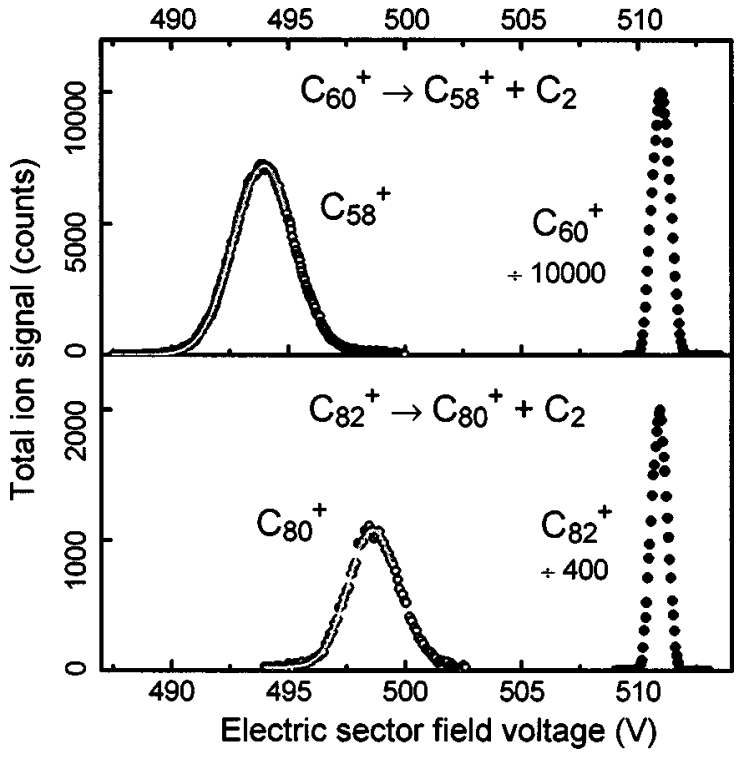

FIG. 2. MIKE spectra (open circles) for unimolecular dissociation of $\mathrm{C}_{60}{ }^{+}$ and $\mathrm{C}_{82}{ }^{+}$(top and bottom panel, respectively). The solid lines represent fits that include instrumental broadening as inferred from the parent ion peaks (solid circles).

on the experimental time scale because their rate coefficients are low, and therefore this subensemble will not affect the KER that is being measured.

Figure 2 displays MIKE scans for unimolecular dissociation of $\mathrm{C}_{n}{ }^{+}$; they are representative of other MIKE scans recorded in the third field free region. The parent ion appears at a sector field voltage of about $511 \mathrm{eV}$; the fragment ion at a voltage as given by Eq. (5). The ratio of the peak amplitudes of parent and fragment ion is not to scale; the former has been reduced as indicated in Fig. 2. The shape of the fragment peak reflects the KERD; its width (corrected for the width of the parent) scales as the square of the average KER. It is obvious from these spectra that the fragment ion peaks are broadened dramatically, and that the statistical quality of the data is high in comparison to other published KER measurements on fullerene ions.

In Fig. 3 we present the average KER obtained from the

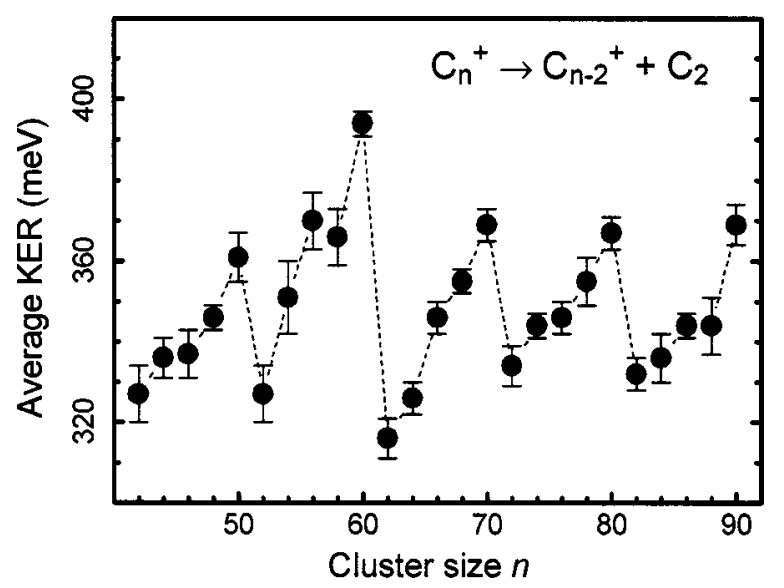

FIG. 3. Average kinetic energy release for unimolecular loss of $\mathrm{C}_{2}$ from fullerene ions $\mathrm{C}_{n}{ }^{+}$derived from experimental MIKE peaks.
TABLE I. Average kinetic energy release (in $\mathrm{meV}$ ) measured in the present work for selected sizes, and comparison with published values.

\begin{tabular}{|c|c|c|c|c|c|}
\hline $\begin{array}{l}\text { Parent } \\
\text { ion }\end{array}$ & This work & Matt et al. ${ }^{\mathrm{a}}$ & Laskin et al. ${ }^{\mathrm{b}}$ & Cao et $a .^{\mathrm{c}}$ & Peres et al. ${ }^{\mathrm{d}}$ \\
\hline $\mathrm{C}_{58}{ }^{+}$ & $366 \pm 7$ & $460 \pm 120$ & & & \\
\hline $\mathrm{C}_{60}^{+}$ & $394 \pm 3$ & 400 & & 450 & \\
\hline $\mathrm{C}_{80}{ }^{+}$ & $367 \pm 4$ & & & & $460 \pm 10$ \\
\hline $\mathrm{C}_{82}{ }^{+}$ & $332 \pm 4$ & & $350 \pm 20$ & & \\
\hline $\mathrm{C}_{84}+$ & $336 \pm 4$ & & $450 \pm 20$ & & \\
\hline
\end{tabular}

${ }^{\mathrm{a}}$ Reference 36.

${ }^{\mathrm{b}}$ Reference 55.

${ }^{\mathrm{c}}$ Reference 56.

${ }^{\mathrm{d}}$ Reference 34 .

MIKE spectra, together with statistical errors extracted from the fitting routine. ${ }^{40}$ The local anomalies at $n=50,60,70$, and 80 greatly exceed the error bars.

Selected values from Fig. 3 are compared with some published values in Table I; for a compilation of data reported prior to 1999 see Ref. 43. The present values have significantly smaller uncertainties than all previously published data. We also note that the steep drop in the average KER from $\mathrm{C}_{80}{ }^{+}$to $\mathrm{C}_{82}{ }^{+}$agrees with observations reported by Lifshitz and co-workers, ${ }^{34,55}$ although it is less dramatic in our experiments. In general, the agreement between values from different experiments for one and the same size is poor. Previously published values tend to be higher; part of this disagreement probably arises from the neglect of the effect of isotopomers on the MIKE peak in earlier work. However, data compared with different instruments cannot be compared directly unless they monitor reaction (2) in identical time windows because the emission temperature of the clusters will decrease due to dissociation and radiation.

Similarly, a comparison with the average KER of thermally emitted delayed electrons reported by Bordas and co-workers ${ }^{57}$ would have to take into account a number of differences between the two experiments. We will return to this topic further below.

\section{B. Dissociation energies of charged and neutral fullerenes}

From the experimentally determined average KER values we compute dissociation energies with the help of Eqs. (4), (7), (8), and (10) assuming $A_{n}=2 \times 10^{19} \mathrm{~s}^{-1}$ for all $n$. The results are displayed in Fig. 4 as full circles. Note that these values are corrected for the estimated effect of radiative cooling (see Sec. III). If we had ignored radiation by applying Eq. (9) instead of Eq. (10), we would have obtained dissociation energies that are smaller by 0.3 to $0.4 \mathrm{eV}$. Uncertainties shown in Fig. 4 reflect the statistical uncertainty of our kinetic energy release values.

Open triangles in Fig. 4 are values derived by Tomita et $a .^{25}$ from the effect of radiative cooling on the time dependence of the dissociation rate coefficient $k_{n}{ }^{+}$. Like us, the authors assumed $A_{n}=2 \times 10^{19} \mathrm{~s}^{-1}$ for all $n$. The open squares in Fig. 4 have been determined from metastable fractions by Barran et al. ${ }^{15}$ This technique does not provide absolute values; we have normalized them to our value for $\mathrm{C}_{54}{ }^{+}$as suggested by Barran et al.; their value for $\mathrm{C}_{60}{ }^{+}$was 


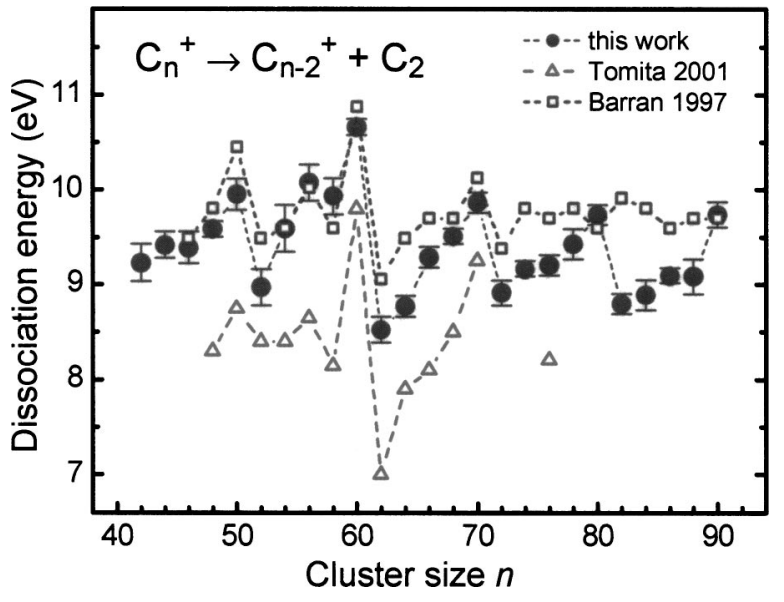

FIG. 4. Dissociation energies for $\mathrm{C}_{2}$ loss from fullerene cations. Filled circles: calculated from kinetic energies (Fig. 3) using the concept of microcanonical temperature and an Arrhenius factor $A=2 \times 10^{19} \mathrm{~s}^{-1}$ for all sizes. The data have been corrected for the effect of radiative cooling. Open squares (Ref. 15) and open triangles (Ref. 25) are from the literature; they were computed from measured unimolecular fractions and rates of dissociation, respectively. The values from Ref. 15 are not absolute; they have been scaled to match our experimental value for $\mathrm{C}_{54}{ }^{+}$.

possibly effected by saturation. Several other experimental studies of the size dependence of $D_{n}{ }^{+}$have been reported $^{24,32}$ (see Ref. 58 for a more comprehensive list). However, they cover narrow size ranges and are not shown here.

Several features in Fig. 4 are reproduced by all three measurements, in particular, the steep drop at $n=60$, and smaller drops at $n=50$ and 70. Our data track Barran's data ${ }^{15}$ remarkably well for small fullerenes. For $n \leqslant 72$ all local anomalies are reproduced, but there is a discrepancy at $n$ $=80$ : Our KERD data, as well as those by Lifshitz and co-workers, ${ }^{34,55}$ suggest a drop from $D_{80}{ }^{+}$to $D_{82}{ }^{+}$. On the other hand, neither the metastable fractions ${ }^{15}$ nor the abundance spectrum in Fig. 1 suggests that $\mathrm{C}_{80}{ }^{+}$has enhanced stability. This discrepancy deserves further study.

The agreement with the data by Tomita et al. (which, like ours, provide absolute values) is less satisfying. On average, our values are $13 \%$ higher than theirs. The discrepancies may be due to unidentified systematic errors; we will return to this issue at the end of this paper.

Equation (3) allows to derive dissociation energies for neutral fullerenes from our data. Ionization energies of fullerenes other than $\mathrm{C}_{60}$ and $\mathrm{C}_{70}$ have been determined by experiment ${ }^{16,59}$ and theory. ${ }^{10,16,60}$ The only study that completely covers the size range of our data is the one by Boltalina et al. ${ }^{16}$ The authors measured adiabatic ionization energies for $n \geqslant 70$ by ion-molecule equilibria Knudsen cell mass spectrometry, and computed adiabatic values for $n$ $\leqslant 84$ by a density-functional-based tight-binding scheme. We use their computed values for $n \leqslant 80$ and experimental values above, because at $n=80$ both data sets yield very similar values for $I E_{n}-I E_{n-2}$.

The values for $D_{n}$ are presented in Fig. 5 by solid circles. The uncertainty introduced in the conversion from $D_{n}{ }^{+}$to $D_{n}$ has been estimated from the standard deviation of the difference in the values of $I E_{n}-I E_{n-2}$ between experi-

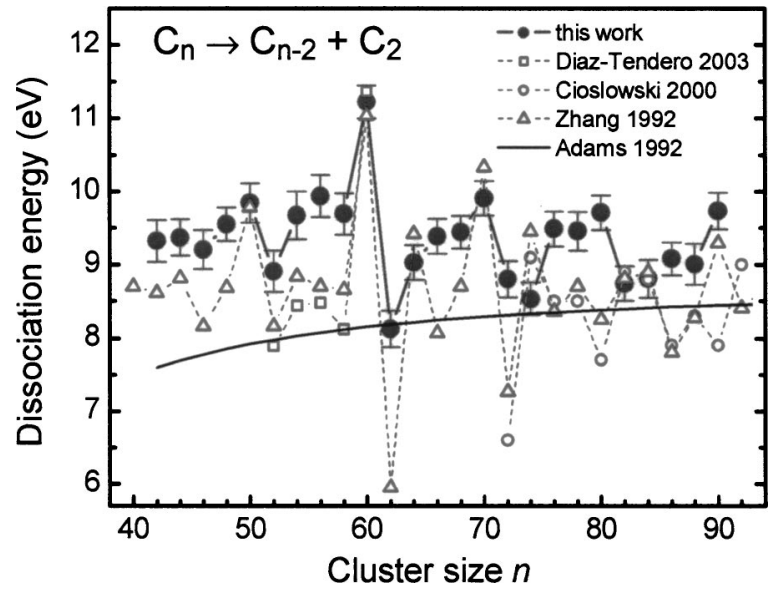

FIG. 5. Dissociation energies for $\mathrm{C}_{2}$ loss from neutral fullerenes. Filled circles have been computed from our experimental dissociation energies for cations and published adiabatic ionization energies (Ref. 16) with the help of Eq. (3). Open symbols are theoretical values derived using various ab initio methods (Refs. 10-12). The solid line is constructed from an empirical equation for the energies of icosahedral fullerenes $\mathrm{C}_{60}, \mathrm{C}_{80}, \mathrm{C}_{140}$, etc. (Ref. 13).

ment and theory, for the size range where the two data sets overlap. The result, $\sigma=0.21 \mathrm{eV}$, has been combined with the statistical error of $D_{n}{ }^{+}$.

Also shown in Fig. 5 are dissociation energies reported by Diaz-Tendero, Alcami, and Martin ${ }^{10}$ using density functional theory (open squares), and by Zhang et al. ${ }^{11}$ using tight-binding molecular dynamics (open triangles).

Cioslowski $^{12}$ has computed standard enthalpies of formation at the B3LYP/6-31G* level for the reaction $(n / 60) \mathrm{C}_{60} \rightarrow \mathrm{C}_{n}$, using the experimental value of $\Delta H_{f}^{0}\left(\mathrm{C}_{60}, g\right)=26.82 \mathrm{eV}$ (Ref. 61) for the standard enthalpy of formation for gas-phase $\mathrm{C}_{60}$. We have deduced $D_{n}$ values from Cioslowski's data (open circles in Fig. 5) using $\Delta H_{f}^{0}\left(\mathrm{C}_{2}, g\right)=8.68 \mathrm{eV}$ for the standard heat of formation of gas-phase $\mathrm{C}_{2} .{ }^{62}$ The solid line in Fig. 5 is derived similarly, from an analytical expression for the total energy of fullerenes in $I_{h}$ symmetry $(n=60,80,140,180,240)$ computed by Adams et al. ${ }^{13}$ using first principles. This curve merely indicates the trend of increasing $D_{n}$ with increasing size $n$, and its extrapolation to sizes below $n=60$ may be questionable.

For $48 \leqslant n \leqslant 72$ the trend in the experimental data agrees quite well with the theoretical values by Zhang et al. ${ }^{11}$ and Diaz-Tendero, Alcami, and Martin ${ }^{10}$ although the extrema, especially the minima for $n=62$ and 72, are significantly less pronounced in the experimental data. Beyond $n=72$ there is little, if any, correlation between the three available data sets. On average, our values exceed those by Zhang et al. by $8 \%$, and those by Diaz-Tendero et al. by $12 \%$.

As explained in the Introduction, $D_{n}$ values cannot presently be derived from quantities measured in thermodynamic equilibrium. However, experimental or theoretical values for $D_{n}$ should satisfy the following relation:

$$
\Delta H_{f}^{0}\left(\mathrm{C}_{70}, g\right)-\Delta H_{f}^{0}\left(\mathrm{C}_{60}, g\right)-5 \Delta H_{f}^{0}\left(\mathrm{C}_{2}, g\right)=\sum_{n=62}^{70} D_{n} .
$$


Hennrich et $\mathrm{al}^{2}{ }^{2}$ quoted a value of $40.59 \mathrm{eV}$ for the left-hand side of Eq. (11). Therefore, the average value of $D_{n}$ over the range $62 \leqslant n \leqslant 70$ should be $\overline{D_{n}}=8.12 \mathrm{eV}$. It is worth to reexamine this value using more recent thermodynamic data. In Ref. 1 nine values for $\Delta H_{f}^{0}\left(\mathrm{C}_{60}, s\right)$ are compiled. One of them, by Steele et al. ${ }^{63}$ appears to be an outlier. The nonweighted average of the remaining eight values is 23.92 $\pm 0.37 \mathrm{eV}$. Combined with the standard heat of sublimation of $\mathrm{C}_{60}, 2.37 \pm 0.08 \mathrm{eV}$, a value of $26.29 \pm 0.38 \mathrm{eV}$ is obtained for $\Delta H_{f}^{0}\left(\mathrm{C}_{60}, g\right)$. For $\mathrm{C}_{70}$, three measurements are listed in Ref. 64. If we discard the early value by Kiyobayashi and Sakiyama, ${ }^{65}$ we find an average of $\Delta H_{f}^{0}\left(\mathrm{C}_{70}, g\right)=28.78$ $\pm 0.38 \mathrm{eV}$ where we have assumed that the accuracy of experiments on $\mathrm{C}_{70}$ is no better than for $\mathrm{C}_{60}$. Combined with the NIST value for $\Delta H_{f}^{0}\left(\mathrm{C}_{2}, g\right)$ and neglecting its uncertainty, we obtain $40.93 \pm 0.54 \mathrm{eV}$ for the left-hand side of Eq. (11), or $\overline{D_{n}}=8.19 \pm 0.11 \mathrm{eV}$.

Our experimental average is larger by $0.99 \mathrm{eV}$, or $12.1 \%$. A similarly large discrepancy was noted above when we compared our results with values measured by Tomita et al. ${ }^{25}$ and with theoretical values. ${ }^{10,11}$ Furthermore, it is instructive to compare the average kinetic energy that we have measured for dissociation of $\mathrm{C}_{60}{ }^{+}$(Fig. 3) with the average kinetic energy of electrons emitted from photoexcited neutral $\mathrm{C}_{60}$ as measured by Bordas and co-workers. ${ }^{57}$ When one computes the parent temperatures from these data with the help of Eq. (8) and corrects for various differences between the two experiments such as the relation between KER and $T_{f}$, time scale, activation energy, etc., one is left with a discrepancy of $18 \%$.

What are the possible sources of error? First, in our analysis we have assumed an $A$ factor of $2 \times 10^{19} \mathrm{~s}^{-1}$ for all sizes. This value is derived indirectly, from the competition between different cooling channels for highly excited $\mathrm{C}_{60}{ }^{+}$; its accuracy is unknown. We can bring our experimental $\overline{D_{n}}$ value into agreement with the thermodynamic value if we assume $A=6 \times 10^{17} \mathrm{~s}^{-1}$ in the data analysis; this is about 1.5 orders of magnitude lower than the preferred $A$ factors used in other recent reports. ${ }^{25,37,48}$

Second, we have adopted the usual assumption that $A_{n}$ is independent of size. Recently, Andersen and co-workers ${ }^{26}$ have measured the time dependence of electron emission from $\mathrm{C}_{60}$ and its neutral fragment $\mathrm{C}_{58}$. From a comprehensive data analysis that included radiative cooling and $\mathrm{C}_{2}$ emission as competing channels, they concluded that the $A$ factor of neutral $\mathrm{C}_{60}$ is higher than that of $\mathrm{C}_{58}$ by more than two orders of magnitude. In the course of the experiments described here, we have determined the metastable fractions for fullerene ions of size $42 \leqslant n \leqslant 70$. These data provide information that is complementary to the kinetic energy release. For most sizes we can model the local anomalies in the metastable fractions with the dissociation energies derived in our current work with a common $A$ factor. However, there are a few sizes in the vicinity of $\mathrm{C}_{60}$ which suggest that the size dependence of $A_{n}$ cannot be neglected. ${ }^{66}$ How large an effect this will have on derived dissociation energies remains to be seen.

Third, the kinetic energy distributions from which our results are derived show a surprising feature. As discussed in detail elsewhere, ${ }^{40}$ the distributions are best described by a pure Langevin-type interaction between the two fragments $\mathrm{C}_{n-2}{ }^{+}+\mathrm{C}_{2}$, although one would expect a distribution that also reflects the hard-sphere cross section of the fullerene fragment ion. ${ }^{47}$ The energy distribution of the capture cross section, $\sigma(\epsilon)$, affects the relation between the average KER and fragment temperature, Eq. (7). If, for example, the sticking probability for the reverse reaction were energy dependent, then an analysis of energy distributions could possibly result in an erroneous assignment of the fragment temperature and, hence, the dissociation energy.

\section{CONCLUSION}

We have determined the KER distributions for unimolecular $\mathrm{C}_{2}$ loss from fullerene cations $\mathrm{C}_{n}{ }^{+}$of size $42 \leqslant n$ $\leqslant 90$. The concept of microcanonical temperature together with an estimate of radiative cooling was used to derive dissociation energies. For $n \leqslant 72$ our data compare quite well with relative dissociation energies that Barran et al. ${ }^{15}$ derived from measured metastable fractions, but a significant disagreement is found for $\mathrm{C}_{80}{ }^{+}$. The agreement with dissociation energies determined by Tomita $e t$ al. $^{25}$ with a different method is less satisfactory. On average, our values are higher by $13 \%$.

Dissociation energies of neutrals are computed with help of experimental and theoretical adiabatic ionization energies reported by Boltalina et al. ${ }^{16}$ For $48 \leqslant n \leqslant 72$ the trend in the experimental dissociation energies agrees quite well with published theoretical values, ${ }^{10,11}$ although the local extrema, especially the minima for $n=62$ and 72, are significantly less pronounced in the experimental data. Beyond $n=72$ there is little, if any, correlation between our experimental and theoretical $^{11,12}$ values. Our dissociation energies averaged over $62 \leqslant n \leqslant 70$ exceed the thermodynamic value by $12 \%$. Approximately the same disagreement is observed when our data are compared with theoretical values for $52 \leqslant n \leqslant 60 .{ }^{10}$ These discrepancies deserve further investigation.

\section{ACKNOWLEDGMENTS}

This work was partially supported by the FWF, Wien and the European Commission, Brussels. We thank J. U. Andersen for constructive remarks on earlier versions of the manuscript and for advice on radiative cooling and comparison of data measured with different experimental approaches.

\footnotetext{
${ }^{1}$ A. Rojas-Aguilara, J. Chem. Thermodyn. 34, 1729 (2002).

${ }^{2}$ F. H. Hennrich, H. J. Eisler, S. Gilb, P. Gerhardt, R. Wellmann, R. Schulz, and M. M. Kappes, Ber. Bunsenges. Phys. Chem. 101, 1605 (1997).

${ }^{3}$ W. Y. Qian, M. D. Bartberger, S. J. Pastor, K. N. Houk, C. L. Wilkins, and Y. Rubin, J. Am. Chem. Soc. 122, 8333 (2000).

${ }^{4}$ C. Piskoti, J. Yarger, and A. Zettl, Nature (London) 393, 771 (1998); A. Koshio, M. Inakuma, Z. W. Wang, T. Sugai, and H. Shinohara, J. Phys. Chem. B 104, 7908 (2000).

${ }^{5}$ H. Prinzbach, A. Weller, P. Landenberger, F. Wahl, J. Worth, L. T. Scott, M. Gelmont, D. Olevano, and B. von Issendorff, Nature (London) 407, 60 (2000); Z. Iqbal, Y. Zhang, H. Grebel et al., Eur. Phys. J. B 31, 509 (2003).

${ }^{6}$ H. Kietzmann, R. Rochow, G. Ganteför, W. Eberhardt, K. Vietze, G. Seifert, and P. W. Fowler, Phys. Rev. Lett. 81, 5378 (1998).

${ }^{7}$ P. R. C. Kent, M. D. Towler, R. J. Needs, and G. Rajagopal, Phys. Rev. B
} 
62, 15394 (2000); B. Paulus, Phys. Chem. Chem. Phys. 5, 3364 (2003); R. O. Jones, J. Chem. Phys. 110, 5189 (1999).

${ }^{8}$ Z. F. Chen and W. Thiel, Chem. Phys. Lett. 367, 15 (2003).

${ }^{9}$ A. D. Boese and G. E. Scuseria, Chem. Phys. Lett. 294, 233 (1998).

${ }^{10}$ S. Diaz-Tendero, M. Alcami, and F. Martin, J. Chem. Phys. 119, 5545 (2003).

${ }^{11}$ B. L. Zhang, C. H. Xu, C. Z. Wang, C. T. Chan, and K. M. Ho, Phys. Rev. B 46, 7333 (1992).

${ }^{12}$ J. Cioslowski, N. Rao, and D. Moncrieff, J. Am. Chem. Soc. 122, 8265 (2000).

${ }^{13}$ G. B. Adams, O. F. Sankey, J. B. Page, M. Okeeffe, and D. A. Drabold, Science 256, 1792 (1992).

${ }^{14}$ N. Park, K. Lee, S. W. Han, J. J. Yu, and J. Ihm, Phys. Rev. B 65, 121405 (2002).

${ }^{15}$ P. E. Barran, S. Firth, A. J. Stace, H. W. Kroto, K. Hansen, and E. E. B. Campbell, Int. J. Mass Spectrom. Ion Processes 167/168, 127 (1997).

${ }^{16}$ O. V. Boltalina, I. N. Ioffe, L. N. Sidorov, G. Seifert, and K. Vietze, J. Am. Chem. Soc. 122, 9745 (2000)

${ }^{17}$ M. Vogel, K. Hansen, A. Herlert, and L. Schweikhard, J. Phys. B 36, 1073 (2003).

${ }^{18}$ J. Laskin, C. Weickhardt, and C. Lifshitz, Int. J. Mass Spectrom. Ion Processes 161, L7 (1997).

${ }^{19}$ A. A. Shvartsburg, R. R. Hudgins, P. Dugourd, R. Gutierrez, T. Frauenheim, and M. F. Jarrold, Phys. Rev. Lett. 84, 2421 (2000); M. F. Budyka, T. S. Zyubina, A. G. Ryabenko, V. E. Muradyan, S. E. Esipov, and N. I. Cherepanova, Chem. Phys. Lett. 354, 93 (2002).

${ }^{20}$ Y. Y. Xia, Y. G. Mu, Y. L. Xing, R. J. Wang, C. Y. Tan, and L. M. Mei, Phys. Rev. B 57, 14950 (1998); M. F. Budyka, T. S. Zyubina, and A. G. Ryabenko, Int. J. Quantum Chem. 88, 652 (2002).

${ }^{21}$ C. E. Klots, Z. Phys. D: At., Mol. Clusters 20, 105 (1991); 21, 335 (1991).

${ }^{22}$ K. Hansen and E. E. B. Campbell, J. Chem. Phys. 104, 5012 (1996); V. Foltin, M. Foltin, S. Matt, P. Scheier, M. Becker, H. Deutsch, and T. D. Märk, Chem. Phys. Lett. 289, 181 (1998).

${ }^{23}$ K. Hansen and O. Echt, Phys. Rev. Lett. 78, 2337 (1997).

${ }^{24}$ J. Laskin, B. Hadas, T. D. Märk, and C. Lifshitz, Int. J. Mass. Spectrom. 177, L9 (1998).

${ }^{25}$ S. Tomita, J. U. Andersen, C. Gottrup, P. Hvelplund, and U. V. Pedersen, Phys. Rev. Lett. 87, 073401 (2001).

${ }^{26}$ S. Tomita, J. U. Andersen, K. Hansen, and P. Hvelplund, Chem. Phys. Lett. 382, 120 (2003).

${ }^{27}$ K. Hansen and E. E. B. Campbell, Int. J. Mass. Spectrom. 233, 215 (2004).

${ }^{28}$ J. U. Andersen, E. Bonderup, K. Hansen, P. Hvelplund, B. Liu, U. V. Pedersen, and S. Tomita, Eur. Phys. J. D 24, 191 (2003).

${ }^{29}$ Y. Basir and S. L. Anderson, J. Chem. Phys. 107, 8370 (1997).

${ }^{30}$ R. Deng and O. Echt, Chem. Phys. Lett. 353, 11 (2002).

${ }^{31}$ M. Foltin, M. Lezius, P. Scheier, and T. D. Märk, J. Chem. Phys. 98, 9624 (1993).

${ }^{32}$ R. Wörgötter, B. Dünser, P. Scheier, T. D. Märk, M. Foltin, C. E. Klots, J. Laskin, and C. Lifshitz, J. Chem. Phys. 104, 1225 (1996); S. Matt, O. Echt, R. Wörgötter, P. Scheier, C. E. Klots, and T. D. Märk, Int. J. Mass Spectrom. Ion Processes 167/168, 753 (1997).

${ }^{33}$ J. Laskin and C. Lifshitz, Int. J. Mass. Spectrom. 36, 459 (2001).

${ }^{34}$ T. Peres, B. P. Cao, H. Shinohara, and C. Lifshitz, Int. J. Mass. Spectrom. 228, 181 (2003).

${ }^{35}$ R. P. Radi, H. Ming-Teh, M. E. Rincon, P. R. Kemper, and M. T. Bowers, Chem. Phys. Lett. 174, 223 (1990); P. Sandler, C. Lifshitz, and C. E. Klots, ibid. 200, 445 (1992); P. Scheier, B. Dünser, and T. D. Märk, J. Phys. Chem. 99, 15428 (1995).

${ }^{36}$ S. Matt, M. Sonderegger, R. David, O. Echt, P. Scheier, J. Laskin, C. Lifshitz, and T. D. Märk, Chem. Phys. Lett. 303, 379 (1999).

${ }^{37}$ S. Matt, R. Parajuli, A. Stamatovic, P. Scheier, T. D. Märk, J. Laskin, and C. Lifshitz, Eur. Mass Spectrom. 5, 477 (1999).
${ }^{38}$ K. Gluch, Physics Doctoral thesis, Universität Innsbruck, 2003.

${ }^{39}$ K. Gluch, S. Matt-Leubner, L. Michalak, O. Echt, A. Stamatovic, P. Scheier, and T. D. Märk, J. Chem. Phys. 120, 2686 (2004).

${ }^{40}$ K. Gluch, S. Matt-Leubner, O. Echt, R. Deng, J. U. Andersen, P. Scheier, and T. D. Märk, Chem. Phys. Lett. 385, 449 (2004).

${ }^{41}$ T. Drewello, K. D. Asmus, J. Stach, R. Herzschuh, M. Kao, and C. S. Foote, J. Phys. Chem. 95, 10554 (1991); D. Schröder and D. Sülzle, J. Chem. Phys. 94, 6933 (1991); M. T. Bowers, P. P. Radi, and M. T. Hsu, ibid. 94, 6934 (1991)

${ }^{42}$ K. Gluch, J. Fedor, S. Matt-Leubner, O. Echt, A. Stamatovic, M. Probst, P. Scheier, and T. D. Märk, J. Chem. Phys. 118, 3090 (2003).

${ }^{43}$ S. Matt, M. Sonderegger, R. David, O. Echt, P. Scheier, J. Laskin, C. Lifshitz, and T. D. Märk, Int. J. Mass. Spectrom. 187, 813 (1999).

${ }^{44}$ J. L. Holmes and A. D. Osborne, Int. J. Mass Spectrom. Ion Phys. 23, 189 (1977); K. Vekey and Z. Szilagyi, Int. J. Mass Spectrom. Ion Processes 165, 1 (1997).

${ }^{45}$ V. Weisskopf, Phys. Rev. 52, 295 (1937); K. Hansen and U. Näher, Phys. Rev. A 60, 1240 (1999).

${ }^{46}$ J. U. Andersen, E. Bonderup, and K. Hansen, J. Chem. Phys. 114, 6518 (2001).

${ }^{47}$ K. Hansen, Chem. Phys. Lett. 383, 270 (2004).

${ }^{48}$ S. Matt, O. Echt, P. Scheier, and T. D. Märk, Chem. Phys. Lett. 348, 194 (2001); C. Lifshitz, Int. J. Mass. Spectrom. 198, 1 (2000).

${ }^{49}$ T. Peres, B. P. Cao, W. D. Cui, A. Khong, R. J. Cross, M. Saunders, and C. Lifshitz, Int. J. Mass. Spectrom. 210, 241 (2001).

${ }^{50}$ K. Hansen, J. U. Andersen, P. Hvelplund, S. P. Möller, U. V. Pedersen, and V. V. Petrunin, Phys. Rev. Lett. 87, 123401 (2001).

${ }^{51}$ J. Laskin and C. Lifshitz, Chem. Phys. Lett. 277, 564 (1997).

${ }^{52}$ F. Rohmund, M. Heden, A. V. Bulgakov, and E. E. B. Campbell, J. Chem. Phys. 115, 3068 (2001); J. U. Andersen, E. Bonderup, and K. Hansen, J. Phys. B 35, R1 (2002).

${ }^{53}$ J. U. Andersen (private communication).

${ }^{54}$ J. U. Andersen, C. Gottrup, K. Hansen, P. Hvelplund, and M. O. Larsson, Eur. Phys. J. D 17, 189 (2001).

${ }^{55}$ J. Laskin, T. Peres, A. Khong, H. A. Jimenez-Vazquez, R. J. Cross, M. Saunders, D. S. Bethune, M. S. DeVries, and C. Lifshitz, Int. J. Mass. Spectrom. 185/186/187, 61 (1999).

${ }^{56}$ B. P. Cao, T. Peres, R. J. Cross, M. Saunders, and C. Lifshitz, J. Phys. Chem. A 105, 2142 (2001).

${ }^{57}$ F. Lepine, B. Climen, F. Pagliarulo, B. Baguenard, M. A. Lebeault, C. Bordas, and M. Heden, Eur. Phys. J. D 24, 393 (2003); F. Lepine and C. Bordas, Phys. Rev. A 69, 053201 (2004).

${ }^{58}$ C. Lifshitz, Int. J. Mass. Spectrom. 200, 423 (2000).

${ }^{59}$ J. A. Zimmermann, J. R. Eyler, S. B. H. Bach, and S. W. McElvany, J. Chem. Phys. 94, 3556 (1991); H. Steger, J. Holzapfel, A. Hielscher, W. Kamke, and I. V. Hertel, Chem. Phys. Lett. 234, 455 (1995).

${ }^{60}$ G. Seifert, K. Vietze, and R. Schmidt, J. Phys. B 29, 5183 (1996); S. Leach, Can. J. Phys. 79, 501 (2001).

${ }^{61}$ X. W. An, J. He, and Z. Bi, J. Chem. Thermodyn. 28, 1115 (1996); V. P. Kolesov, S. M. Pimenova, V. K. Pavlovich, and N. B. Tamm, ibid. 28, 1121 (1996)

${ }^{62}$ NIST Chemistry WebBook, http://webbook.nist.gov/

${ }^{63}$ W. V. Steele, R. D. Chirico, N. K. Smith, W. E. Billups, P. R. Elmore, and A. E. Wheeler, J. Phys. Chem. 96, 4731 (1992).

${ }^{64}$ H. P. Diogo, M. E. M. Dapiedade, A. D. Darwish, and T. J. S. Dennis, J. Phys. Chem. Solids 58, 1965 (1997).

${ }^{65}$ T. Kiyobayashi and M. Sakiyama, Fullerene Sci. Technol. 1, 269 (1993).

${ }^{66}$ B. Concina, K. Gluch, S. Matt-Leubner, O. Echt, P. Scheier, and T. D. Märk, 14th Symposium on Atomic, Cluster and Surface Physics, La Thuile, Italy, 2004, edited by P. Casavecchia, 2004, p. PB8. 